\title{
Keeping Kids in School: \\ A Study Examining the Long-Term Impact of Afterschool Enrichment Programs on Students' High School Dropout Rates
}

\author{
Denise Huang \\ CRESST/University of California Los Angeles \\ dhuang@cse.ucla.edu \\ Kyung Sung Kim, \\ CRESST/University of California Los Angeles \\ iuz4ksk@gmail.com \\ Jamie Cho \\ CRESST/University of California Los Angeles \\ jamie118@gmail.com \\ Anne Marshall \\ CRESST/University of California Los Angeles \\ aemarsha@ucla.ca \\ Patricia Pérez \\ California State University, Fullerton \\ pperez@fullerton.edu
}

\begin{abstract}
Despite the potential benefits of afterschool programs, much of the related research has been limited to an examination of only their immediate or short-term effects. The LA's BEST afterschool program has been in operation for more than 20 years, providing researchers with a unique opportunity to explore the long-term effects of afterschool programming. This study examined the dropout rates of the LA's BEST afterschool participants and compared them to a stratified random district sample that was matched to the characteristics of the afterschool students. The results indicated that students who had participated in the afterschool program for at least three years showed a significantly lower dropout rate than the district students overall.
\end{abstract}

\section{Introduction}

In the United States, close to one third of all public high school students and nearly half of all African American, Hispanic, and Native American students do not finish high school every year (Bridgeland, Dilulio, and Morison, 2006). These high school dropouts, with nearly $37 \%$ of them living in poor or near poor families, are more likely to be unemployed throughout the entire calendar year (Sum, Khatiwada, \& McLaughlin, 2009). They are also more likely to become dependent on government assistance (Laird, Kienzl, DeBell, \& Chapman, 2007), become involved in crime (Lochner \& Moretti, 2004), and to use substances such as tobacco, alcohol, marijuana, and other illicit drugs (Townsend, Flisher, \& 
King, 2007). When employed, according to the United States Bureau of the Census (2010), the average annual earnings of someone without a high school diploma in 2007 was $\$ 21,484$ while those with a high school diploma earned $\$ 31,286$ - a difference of $\$ 9,802$.

Fortunately, there are intervention strategies that can offset the obstacles faced by atrisk students and improve their high school graduation rate. Among the most frequently mentioned strategies are early identification and intervention, the provision of a safe learning environment, and on-going school and community collaboration (Smink \& Reimer, 2005). Because afterschool programs incorporate all of the above strategies, they are possible solutions for supporting at-risk students. Literatures have stated that quality afterschool programs can provide students with safe environments during the afterschool hours where students can engage in extra-curricular activities and academic enrichment that foster academic resilience (Afterschool Alliance, 2009a).

This study intended to examine whether participation in afterschool programs can help reduce the dropout rate of at-risk youth. More specifically, this study investigated the longterm effects of the LA's BEST afterschool program on student dropout rate. LA's BEST serves schools in a large urban school district in California, the Los Angeles Unified School District (LAUSD). Compared to national and state statistics, LAUSD has a high dropout rate. This school district regularly services over 600,000 students annually, and it is estimated that a third of the high school students will not graduate each year. For example, based on the California Department of Education (CDE) statistics, only $72.4 \%$ of high school students within the LAUSD graduated during the 2007-08 academic school year, while the remaining students were not retained. This figure is below the county graduation rate $(77.8 \%)$ as well as the state graduation rate $(80.2 \%)$. It is no surprise, then, that these students would be considered "at-risk." Yet, despite compounding risk factors, many students in the district have managed to successfully navigate the education system and graduate from high school. With these resilient students in mind, this study was designed to investigate whether an afterschool program supporting elementary students can serve as a source of early intervention to improve the dropout rate of at-risk students in this district. Specifically, the study compared the high school dropout rates of students who had participated in the afterschool program at least one year to the dropout rates of those who had not participated. The findings can inform public and private organizations that are interested in promoting educational resiliency in students. Policy makers can also use the results as evidence of the effects of afterschool programs and can assist law enforcement agencies in their quest to reduce juvenile delinquency and crime by keeping students in school.

\section{The Los Angeles Better Educated students for Tomorrow (LA's BEST) Program}

This California-based afterschool program is a comprehensive program based on education principles that foster resilience and success for at-risk students. The program was first implemented in the fall of 1988; it seeks to provide a safe haven for students in neighborhoods where gang violence, drugs, and other types of anti-social behaviors are common. The LA's BEST program provides students with a comprehensive, supervised afterschool setting that includes homework help, extra-curricular activities, nutrition, and supportive adults. The goal of the program is to provide students with the following resources: 
- a safe environment;

- enhanced educational opportunities through the integration of an educational support structure into each student's schedule;

- educational enrichment activities to supplement the regular education program and provide enticement to learn;

- recreational activities; and

- interpersonal skills and self-esteem development.

The program sites are chosen based on criteria such as low academic performance and the schools' locations in low-income, high-crime neighborhoods.

\section{Building Resiliency: The Afterschool Model}

At-risk students face multiple and daily obstacles that may hinder their academic and social development. School factors (e.g., lack of school resources, low teacher or administrative support, safety concerns, lack of afterschool programs, or extracurricular activities), local community factors (e.g., exposure to crime, substance use, or unsafe neighborhoods), and students' home life factors (e.g., lack of parental support, abuse, or poverty) can all contribute to poor academic and social development (Gutman \& Midgley, 2000; Ungar, 2004). Furthermore, at-risk students may face additional obstacles including trauma, poverty, and lack of positive peer and adult interactions (Masten \& Obradovic, 2006). The research indicates that individuals who can overcome such obstacles share common properties of resiliency, such as high self-esteem, positive life attitudes, and high future aspirations (Rouse, Bamaca-Gomez, \& Newman, 2001; Siebert, 2005). These individuals achieve resiliency because they had opportunities to develop affirming personal relationships, to learn about the importance of school, and to gain a sense of well-being, among other positive attributes (Scott-Little, Hamann, \& Jurs, 2002). Quality afterschool programs that focus on building resiliency in students can provide such opportunities (Brooks, 2006; Cooper, Estes, \& Allen, 2004).

Afterschool programs have been found to benefit students in three critical ways. First, they provide students with supervision during a time when they might normally fall prey to deviant or anti-social behaviors-research has revealed that the rates for both juvenile crimes and the victimization of juveniles peak in the afterschool hours (U.S. Department of Education \& U.S. Department of Justice, 2000). Secondly, afterschool programs provide experiences that may benefit students' social skills and work habits (Scott-Little, Hamann, \& Jurs, 2002; Vandell, Reisner, \& Pierce, 2007). Finally, afterschool programs may help to improve academic achievement through tutoring and enrichment activities (Fashola, 2002). These three major factors are important in contributing to and sustaining the resiliency of students who are at risk for academic failure and dropping out.

\section{Evidence on the Benefits of Afterschool Programs}

A review of research and evaluations conducted on LA's BEST over the past 20 years indicates that the program positively impacted participants' resiliency. These findings are outlined below and categorized according to safety, social development, and academic enrichment. As previously mentioned, these key findings highlight the crucial elements of afterschool programs that could inherently lead to resiliency and facilitate school retention. 
Safety. Over the past two decades, the increasing crime rate, the availability of weapons, and the growth of drug subcultures have made many communities and neighborhoods dangerous for children and adolescents (Alliance for Excellent Education, 2009; Fight Crime: Invest in Kids California, 2007). These risks appear to peak during the afterschool hours (Afterschool Alliance, 2009b; U.S. Department of Education \& U.S. Department of Justice, 2000). Therefore, safe environments have become fundamental to the well-being of students living in such communities. Three previous studies on LA's BEST found that the afterschool program had a positive impact on improving feelings of safety. Participants reported feeling safer in the program than in their neighborhoods after school (Huang et al., 2003; Huang, Choi, Henderson, Howie, Kim, Vogel, Waite, et al., 2004; Huang, Gribbons, Kyung, Lee, \& Baker, 2000), while another study found that newly enrolled students felt safer in both home and school environments at the time of the followup survey than they did prior to their enrollment at the LA's BEST sites (Huang, Choi, Henderson, Howie, Kim, Vogel, Waite, et al., 2004). Furthermore, parents also reported that they felt their children were safer after school hours while participating in the program (Huang, Choi, Henderson, Howie, Kim, Vogel, Waite, et al., 2004). These evidences support that the LA's BEST program provides at-risk students a safe afterschool environment that is essential to the development of lasting resiliency.

Social Development. Program climates can also affect students' learning in significant ways. Extant literatures indicate that there are certain environmental features that are associated with greater resilience. For example, afterschool programs can promote resiliency by providing students with an organized, predictable, developmentally appropriate, and culturally relevant afterschool environment (Birmingham, Pechman, Russell, \& Mielke, 2005; Lessard, Fortin, Marcotte, Potvin, \& Royer, 2009; Vandell, Shumow, \& Posner, 2005). When this kind of setting is combined with supportive and caring staff, afterschool programs become ideal places to foster social competence, develop pro-social skills, teach conflict resolution skills, and promote self-esteem and self-efficacy (Durlak \&Weissberg, 2007; Gullota, Bloom, Gullotta, \& Messina, 2009). These types of pro-social behaviors are critical to an individual's and society's well-being (Miller, 2003), and the ability to get along with peers and the ability to act pro-socially are important components to good citizenship (Partnership for the $21^{\text {st }}$ Century Skills, 2009, 2010).

Previous studies conducted on the LA's BEST program found that positive relationships between staff and students were established and that participating students liked school more and were more engaged in school after they enrolled and participated in the program for a year (Huang et al., 2005; Huang, Coordt, et al., 2007; Huang et al., 2000; Huang, Miyoshi, et al., 2007;). The participating students also showed greater confidence in their ability to use conflict resolution skills to solve problems with peers, and they had positive attitudes towards cooperation, sharing, and listening to adults (Huang et al., 2003; Huang et al., 2005). These studies provide evidences that the LA's BEST program helped participants develop social skills and positive relationships considered essential to resiliency.

Academic Enrichment. Quality afterschool programs also offer students opportunities to increase learning. Research found that students attending afterschool programs spend more time in academic and enrichment activities than their peers who do not attend afterschool programs (Posner \& Vandell, 1994). Successful afterschool programs include curricula that contain learning activities and materials that promote higher order thinking and materials that are responsive to students' diversity and needs. These include activities that enhance 
academic skills, such as tutoring, reading enrichment programs, and activities linking the afterschool curriculum with the regular school program. This type of learning experience enhances students' motivation and serves as a protective factor that promotes educational resilience and learning success (Durlak \& Weissberg, 2007; Arbreton, Sheldon, Bradshaw, \& Goldsmith, 2008).

LA's BEST provides a variety of academic enrichment activities for participating students after school hours, five days a week; LA's BEST also provides field trips, sports, and cultural events on weekends. Research on the LA's BEST program has found several indications of positive influence on student academics. These studies have found influences on both day school attendance and academic achievement. For instance, one study used path analysis to examine program participation, school attendance, and standardized test scores. The results indicated that higher levels of participation in the LA's BEST afterschool program led to better school attendance and higher scores on subsequent testing (Huang et al., 2000). Other studies on LA's BEST have resulted in similar findings (Huang, Choi, Henderson, Howie, Kim, Vogel, Waite, et al., 2004; Huang, Choi, Henderson, Howie, Kim, Vogel, Yoo, et al., 2004; Huang, De Vries, et al., 2004; Huang, Leon, La Torre, \& Mostafavi, 2008).

In summary, these findings suggest that the LA's BEST program provides a structure in which students can develop resiliency. Not only did students feel safe at the afterschool program, but they also received opportunities for social development through positive relationships with trusted mentors and academic enrichment through afterschool activities such as tutoring. These opportunities are all essential elements for strengthening students' resiliency

\section{Method}

In this study, four cohorts of students, one for each grade from $6^{\text {th }}$ to $9^{\text {th }}$ grade, were examined. Each cohort was divided into two groups: afterschool participants and student non-participants. Using descriptive statistics, ${ }^{1}$ chi-square analyses, ${ }^{2}$ and Cox survival analysis, ${ }^{3}$ this study examined the impact of participation in an afterschool program on high school dropout rates. In addition, the study also examined the varying effect of participation in afterschool program on dropout rates for different gender, language, income level, and ethnic groups.

\section{Data Sources}

For attendance and dropout measures, the study drew from the longitudinal student database of the LAUSD school district. Afterschool program attendance records from the LA's BEST program were used to identify the program participants within the LAUSD

\footnotetext{
${ }^{1}$ Descriptive statistics provide general description of the data collected, such as means, frequencies, sample size, and sample demographics.

${ }^{2}$ The chi-square analysis is generally used when there is a need to examine the similarities between two or more variables on some characteristics of interest. While other statistical tests conduct pair-wise comparisons, the chisquare can handle more than one variable or population at the same time.

${ }^{3}$ Cox survival analysis relates the time that passes before an event occurs to one or more of the covariates (variables that are predictive of the outcomes). In a proportional hazards model, the unique effect of a unit increase in a covariate is multiplicative with respect to the hazard rate. For example, taking an aspirin daily may reduce $50 \%$ of one's hazard rate for a stroke occurring.
} 
databases. Longitudinal data were then linked to the program's attendance records to gather further data on the afterschool-participating students' dropout rates.

\section{Sample}

All LA's BEST participants were included in the afterschool sample. Three participation levels (one year, two years, and three or more years of participation) were identified for this investigation to examine the impact of the duration of participation. Additionally, a stratified random sample ${ }^{4}$ of non-participants within the school district database was selected and matched to the characteristics of the afterschool participating students to examine the difference between participants and non-participants in dropout rates.

More specifically, to select the comparison group, the non-participants in the district database were matched with the LA's BEST participants based on school site, grade level, gender, low-income status as indicated by free and reduced-price lunch programs, academic performance, and limited English proficient (LEP) status. A comparison group was then randomly selected from this pool of matched students.

The three participation levels and the comparison group included students from four grade-level cohorts (from sixth through ninth grade) in the 1998-99 academic year. These students were followed until the end of the 2002-03 academic year when they would have been tenth, eleventh, or twelfth graders. Students were counted as participating for the year only if they attended the program for a minimum of 20 days. The number of participants for each of the three levels in both the experimental and comparison groups is presented in Table 1.

Table 1: Participants in the Afterschool Program and Non-participants in Three levels

\begin{tabular}{llll}
\hline & \multicolumn{3}{c}{ Number of participants } \\
\cline { 2 - 4 } & 1 year & 2 years & 3+ years \\
\hline Afterschool participants & 2,967 & 1,636 & 1,224 \\
\hline Non-participants & 2,963 & 1,634 & 1,219 \\
\hline
\end{tabular}

\section{Key Definitions}

For purposes of this study, the definition for "dropout" is anyone who is no longer in the school district database without a plausible leave code. As such, a real dropout rate for the school district would be slightly lower than our results suggest because the students absent from the school district database could possibly include students who had transferred

\footnotetext{
${ }^{4}$ In order to make sure the LA's BEST participants and non-participants are similar to each other, it is advantageous to use stratification as the process of grouping members of these populations into relatively homogeneous subgroups before sampling. In conducting the stratification, the strata should be mutually exclusive, that is, every element in the population must be assigned to only one stratum. The strata should also be collectively exhaustive so that no population element can be excluded. Then random or systematic sampling is applied within each stratum. In other words, each LA's BEST student's characteristics are matched to a nonparticipant. This often improves the representativeness of the sample by reducing sampling error.
} 
out of one school district into another or out of the state altogether without formally informing the district. These transient students, then, are captured within the dropout rates reported in this paper. However, the resulting elevation in dropout rates is assumed to be similar for both the afterschool participants and the non-participants; thus, it should not have influenced the results.

Dropout indicators were calculated for each of the four years analyzed. Students were classified as participating in the afterschool program for the year if they attended a minimum of 20 days during the academic year. Therefore, a student in the three-year participation group would have had to attend the program for a minimum of 20 days in each of three or more different academic years.

\section{Statistical Approach}

Descriptive statistics were used to provide demographic profiles, such as gender, ethnicity, socio-economic level, and language status of the afterschool participants and nonparticipants. In order to determine whether the difference between the dropout rates of participants and non-participants in the sample was statistically significant, chi-square analyses were performed to test for differences, and, if there were differences, whether these differences were significant. In addition, a Cox survival analysis was also conducted to examine the effect of the intensity of participation, gender, ethnicity, low-income status, and LEP status.

The statistical method of Cox regression (under survival analysis) is somewhat different from a traditional regression analysis. In this study, the dependent variable, "dropping out," is represented by the number of years (from one to five) staying in the district schools. Survival analysis was conducted for the time it took students to drop out of the district by using Cox proportional hazards regression. Time to dropout was measured from 1998-99 to 2002-03. Those students who remained in the district by 2003 were considered "survived."

The proportional-hazards assumption is tested by comparing the correlation of each covariate between the students who remained in school and the students who dropped out. A statistically significant correlation between those who stayed in school and those who dropped out indicates a non-proportional hazard for a given covariate. When the correlation is positive, the effect of the covariate increases with time. When the correlation is negative, the effect of the covariate decreases with time. Thus, the negative value of an unstandardized regression coefficient is interpreted as "reducing the hazard of dropping out."

\section{Hypothesis}

Based on previous stated evidences, it was hypothesized that participation in the LA's BEST afterschool program would reduce participants' dropout rate in high school. This study further hypothesized that the more regularly the students participated in the LA's BEST program, the less likely they were to drop out of high school.

\section{Results}

\section{Sample Demographics}

As intended with the use of the stratified sampling methodology, the resulting sample of afterschool participants and non-participants in our student sample shared very similar 
demographic characteristics. The majority of participants in each cohort were female. The highest percentage of students within each of the three samples consisted of sixth graders, followed by seventh graders, and then eighth and ninth graders. Most students were Hispanic, followed by African American, Asian/Pacific Islander, Caucasian students, and students identifying as "other." As for the socio-economic proxy (free and reduced-price lunch), the majority (at least $84 \%$ or more) of afterschool participants and non-participants received a free or reduced-price lunch. Finally, in each of the four cohorts, at least a third or more of afterschool participants and non-participants were LEP students. Since none of the characteristics between afterschool participants and non-participants within each cohort was significantly different, the student characteristics will be displayed across cohorts with participant and non-participant information combined. Table 2 summarizes the gender, grade level, ethnicity, and language characteristics of the study samples.

Table 2: Descriptive Characteristics of Afterschool Participants and Non-participants

Amount of time spent in LA's BEST

\begin{tabular}{lccc}
\hline $\begin{array}{c}\text { Student } \\
\text { Characteristics }\end{array}$ & $\begin{array}{c}\text { One year } \\
(n=5,930)\end{array}$ & $\begin{array}{c}\text { Two years } \\
(n=3,270)\end{array}$ & $\begin{array}{c}\text { Three years } \\
(n=2,443)\end{array}$ \\
\hline Gender & & & $48.6 \%$ \\
Male & $50.8 \%$ & $49.3 \%$ & $51.4 \%$ \\
Female & $49.2 \%$ & $50.7 \%$ & \\
Grade Level & & & $45.2 \%$ \\
$6^{\text {th }}$ grade & $29.6 \%$ & $34.7 \%$ & $35.6 \%$ \\
$7^{\text {th }}$ grade & $29.7 \%$ & $25.6 \%$ & $14.7 \%$ \\
$8^{\text {th }}$ grade & $21.1 \%$ & $25.6 \%$ & $4.4 \%$ \\
$9^{\text {th }}$ grade & $19.5 \%$ & $14.0 \%$ & \\
Ethnicity & & & $78.1 \%$ \\
Hispanic & $75.5 \%$ & $75.6 \%$ & $18.1 \%$ \\
African American & $20.2 \%$ & $20.4 \%$ & $1.4 \%$ \\
Caucasian & $1.7 \%$ & $1.8 \%$ & $1.7 \%$ \\
Asian & $2.2 \%$ & $1.9 \%$ & $0.7 \%$ \\
Other & $0.4 \%$ & $0.3 \%$ & $88.4 \%$ \\
Free/Reduced Lunch & $84.6 \%$ & $86.0 \%$ & $30.3 \%$ \\
LEP & $39.0 \%$ & $34.5 \%$ & \\
\hline
\end{tabular}




\section{Chi-square Analysis}

Chi-square statistics comparing LA's BEST participants with non-participants for each of the three levels of participation were conducted. Results showed no significant differences for any of the four cohorts with one year of participation.

However, although no statistical significant results were found for the sixth-, seventh-, and eighth-grade cohorts, statistically significant differences for two-year participants were found with the cohort whose students began the ninth grade in 1998. Table 3 shows the chisquare statistics of dropout rates for each of the cohorts that participated for two years in the LA's BEST program.

Table 3

Chi-Square Statistics of Dropout Rates (Two-Year Participants)

\begin{tabular}{lllll}
\hline \multicolumn{5}{c}{ Chi-square Value } \\
\hline \multicolumn{1}{c}{ Academic Year } & $99-00$ & $00-01$ & $01-02$ & $02-03$ \\
\hline $6^{\text {th }}$ & 2.534 & 0.699 & 0.005 & 0.004 \\
$7^{\text {th }}$ & 0.067 & 2.189 & 0.124 & 0.597 \\
$8^{\text {th }}$ & 1.519 & 0.839 & 1.040 & 2.781 \\
$9^{\text {th }}$ & $8.138^{* *}$ & $6.982^{*}$ & $9.005^{* *}$ & $\mathrm{n} / \mathrm{a}$ \\
\hline Total & 1.155 & 1.854 & 3.567 & 1.870 \\
\hline
\end{tabular}

Note. *Significant at .05 level; ** Significant at .01 level; *** Significant at .001 level.

To illustrate the widening gap in dropouts between the LA's BEST participants and non-participants, Figure 1 displays the dropout rates for the $9^{\text {th }}$ grade cohort from their ninthgrade to their twelfth-grade years. As Figure 1 shows, the difference in dropout rates for the participants and non-participants begins in the tenth grade and increases through the twelfth grade. 


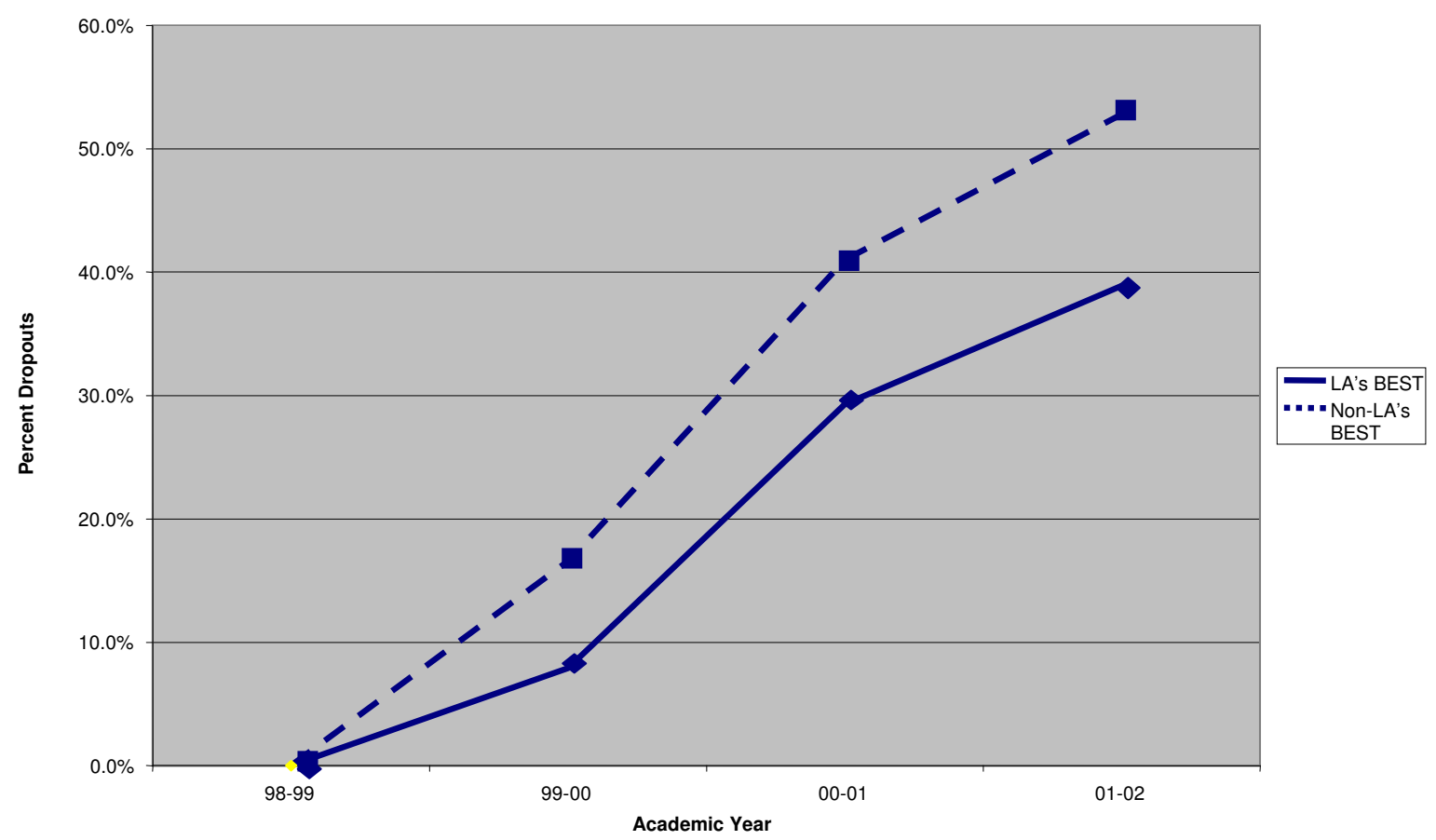

Figure 1. Comparison of dropout rates for LA's BEST participants vs. non-participants (2 years) for the ninth-grade Cohort (began ninth grade in 1998-99).

The chi-square analyses on differences between the LA's BEST participants who had attended the program for three or more years and non-participants showed significant results. Table 4 shows the chi-square statistics of dropout rates for each of the cohorts of LA's BEST students who participated for three or more years. Even though the eighth- and ninth-grade cohorts indicated no difference between the participants and non-participants, when combined, the afterschool program participants had significantly lower dropout rates than the non-participant comparison group. That is, taken as a whole, the non-participant cohorts had a significantly greater percentage of dropouts in the 1999-2000 ( $p<0.01), 2000-01$ $(p<0.001), 2001-02(p<0.001)$, and 2002-03 $(p<0.01)$ academic years than did the LA's BEST cohorts. 
Table 4

Chi-Square Statistics of Dropout Rates (3+ Year Participants)

\begin{tabular}{lcccc}
\cline { 2 - 5 } & \multicolumn{4}{c}{ Chi-square Value } \\
\hline Academic Year & $99-00$ & $00-01$ & $01-02$ & $02-03$ \\
\hline $6^{\text {th }}$ & $4.625^{*}$ & $7.966^{* *}$ & $7.675^{* *}$ & $4.866^{*}$ \\
$7^{\text {th }}$ & 2.946 & $8.606^{* *}$ & $12.343^{* * *}$ & $8.126^{* *}$ \\
$8^{\text {th }}$ & 0.001 & 0.003 & 0.258 & 0.267 \\
$9^{\text {th }}$ & 3.030 & 0.049 & 0.000 & $\mathrm{n} / \mathrm{a}$ \\
Total & $8.004 * *$ & $12.926^{* * *}$ & $13.380^{* * *}$ & $10.220 * *$ \\
\hline
\end{tabular}

Note. *Significant at 0.05 level; ** Significant at 0.01 level; *** Significant at 0.001 level.

Figure 2 illustrates the dropout rates for LA's BEST participants attending the program for at least three years and their comparison non-participants from 1998-1999 to 2002-2003. As the figure indicates, dropout rates were lower for LA's BEST participants, and the difference increased as more of the cohorts entered high school, when students are most likely to dropout.

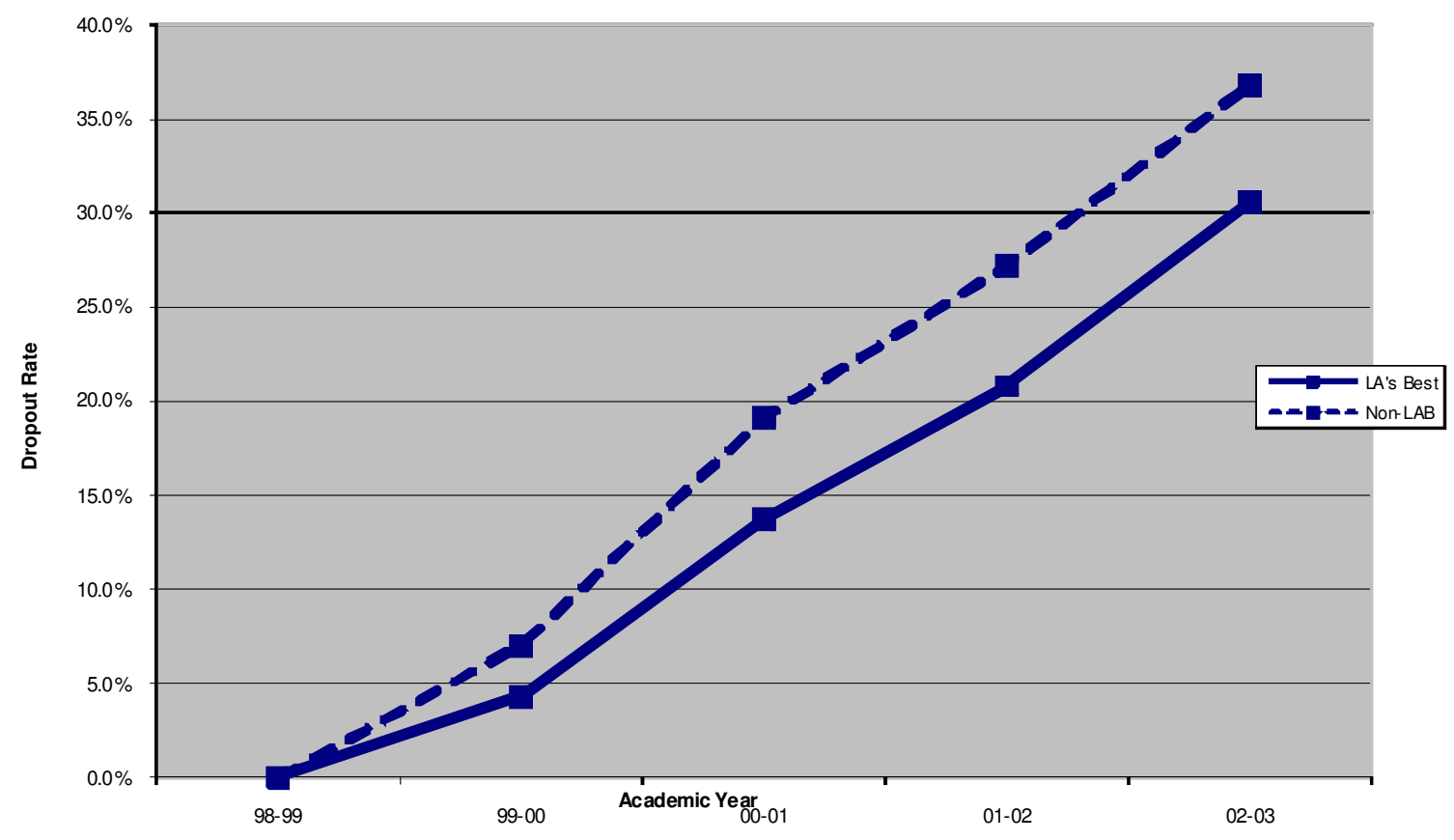

Figure 2. Comparison of dropout rates for LA's BEST vs. LAUSD non-participants (3+ years). 
More specifically, when looking at individual cohort differences at the two-year participation level, the dropout rates for the non-participant cohort (ninth graders in 1998) were significantly higher in the 1999-2000, 2000-01, and 2001-02 school years than for the cohort for LA's BEST. Similarly, for the three-year participation level, the dropout rate for the sixth-grade cohort (sixth grade in 1998) and seventh-grade cohort (seventh grade in 1998) during the 2000-01 to 2002-03 school years was significantly higher for those in the non-participant sample than for those in LA's BEST.

For further investigation, an examination of the attendance data for the three-or-moreyears participants was conducted. Attendance data revealed that the eighth- and ninth-grade cohorts had overall lower intensity-of-participation rates than the other cohorts. Only about $7 \%$ of the ninth-grade cohort and 14\% of the eighth-grade cohort attended LA's BEST for more than 20 days in each of the three or more years. Their low intensity of participation may or may not have contributed to the dropout rate of these two cohorts.

\section{Cox Survival Analysis}

To examine whether the intensity of participation has an effect on the dropout rate, a Cox regression analysis was conducted. For this analysis, the entire LA's BEST population was used $(n=5,283)$. The Cox model is a statistical technique for analyzing survival data. The benefit of this model is that it can also be used, a priori, if it is known that there are other variables besides the treatment (afterschool participation) that influence participant survival (not dropping out of school).

An important feature of survival times is that the event of interest (dropping out of school) is very rarely observed in all students. For example, in a study to compare the survival of cancer patients receiving different types of treatments, even though the patients may be followed for many years, some patients may not survive until the end of the study. The experimenters do not know when these patients will die, only that they are still alive at the end of the study; therefore, their survival times are not known at the start of the treatment, only that it will be longer than their time in the study. Such survival times are termed "censored" to indicate that the period of observation was cut off before the event of interest occurred. Table 5 shows the distribution of the cohorts (stratum) in this study. 
Table 5

Stratum Status

\begin{tabular}{lcccc}
\hline Stratum & $\begin{array}{c}\text { Strata } \\
\text { label }\end{array}$ & Event & Censored & Censored \% \\
\hline 6.00 & $6^{\text {th }}$ grade & 1,032 & 2,623 & $71.8 \%$ \\
7.00 & $7^{\text {th }}$ grade & 1,137 & 2,025 & $64.0 \%$ \\
8.00 & $8^{\text {th }}$ grade & 915 & 1,260 & $57.9 \%$ \\
9.00 & $9^{\text {th }}$ grade & 631 & 872 & $58.0 \%$ \\
Total & & 3,715 & 6,780 & $64.6 \%$ \\
\hline
\end{tabular}

From a set of observed survival times (including censored times), the proportion of the population of such people who would survive a given length of time under the same circumstances can be estimated. This method is called the product limit or Kaplan-Meier method.

In this study, the results of the Kaplan-Meier survival function indicate the proportion of students who stayed in school at each point in time. As shown in Figure 3, this typical s-shaped curve shows that the proportion of students who stayed in school decreased at an increasing rate throughout the four years for each of the cohorts.

Survival Function at mean of covariates

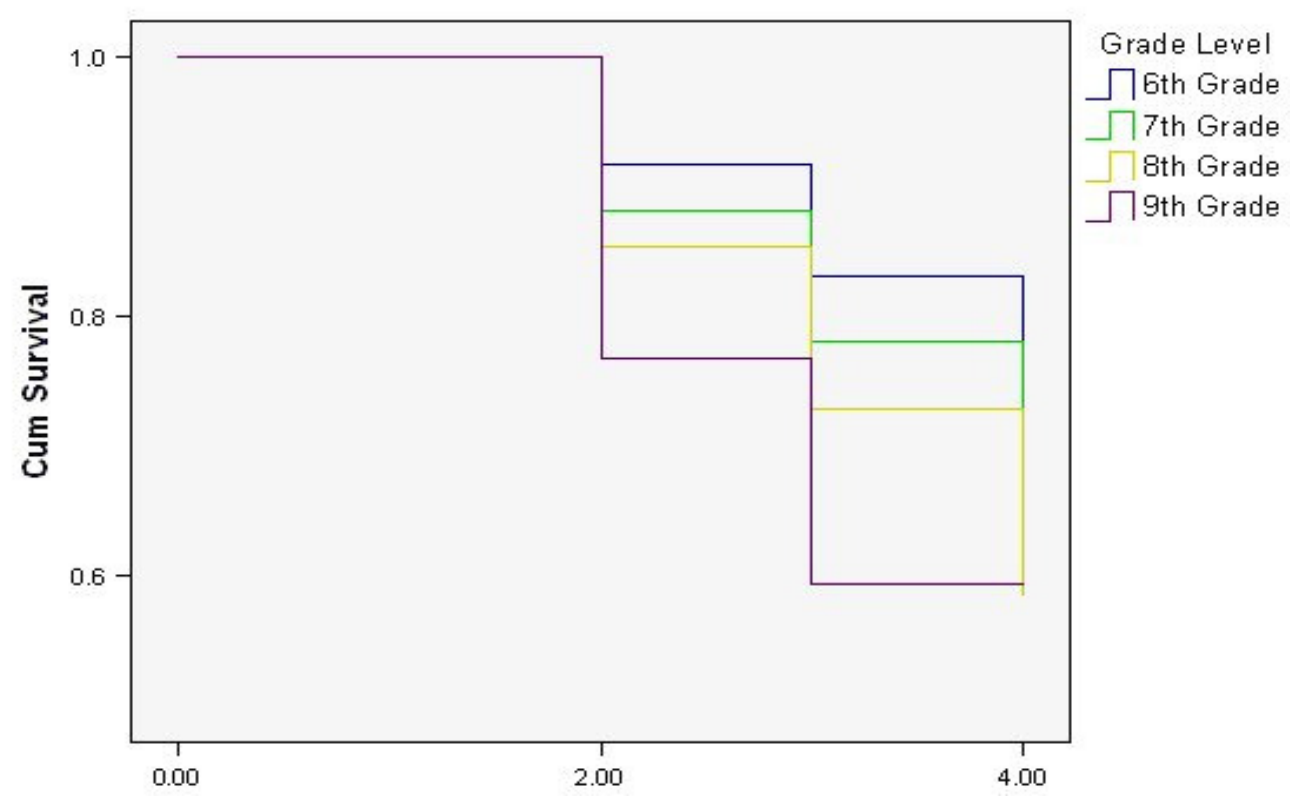


Figure 3. Proportion of students who stayed in school at each point in time. Cum Survival (the $y$-axis) refers to the percentage of cases that have survived at a given point in time (e.g. when the dataset was collected).

The proportional-hazards regression was further carried out by using five covariates, or predictors, of student survival, which were all measured at the time of entry into the study: (a) attendance in LA's BEST, (b) gender, (c) ethnicity, (d) low-income status, and (e) LEP status. Furthermore, the squared terms for these variables were presented to the model to check for non-linear relationships. The results of this regression are shown in Table 6.

Table 6

Cox Regression of Hazard Rate on Characteristics of the Students

\begin{tabular}{lccccc}
\hline Characteristics & $B$ & $S E$ & Wald & Sig & Exp $(B)$ \\
\hline Attendance & -0.001 & 0.000 & 30.980 & 0.000 & 0.999 \\
Gender & 0.066 & 0.033 & 4.076 & 0.043 & 1.069 \\
Ethnicity & 0.210 & 0.092 & 5.193 & 0.023 & 1.234 \\
Low income & -0.251 & 0.045 & 31.094 & 0.000 & 0.778 \\
LEP & 0.155 & 0.034 & 20.382 & 0.000 & 1.168 \\
\hline
\end{tabular}

Note. $-2 \log$ likelihood $=57605.715$. Model chi-square $=93.927 ; d f=5 ; p=0.000 . B=$ Regression coefficient; $S E=$ Standard error; Wald $=$ Wald test (a likelihood to ratio test) $\mathrm{Sig}=$ Test of significance; $\operatorname{Exp}(B)=$ Exponentiated slope.

The slope for dropout was negative and significant. As mentioned in the Method Section, the negative value of the unstandardized regression coefficient is interpreted as "reducing the hazard of dropping out." Thus, this negative slope indicates that the higher the number of participation days in LA's BEST, the lower the hazard of dropping out (Wald test: $\left.\mathrm{X}^{2}[1]=30.980, p<0.000\right)$. In this context, with other factors held constant, regardless of gender, ethnicity, low-income status, and LEP status, those students who participate more frequently in the LA's BEST program are predicted to stay in school longer. In other words, the Cox analysis reveals the importance of the intensity of participation rate: The more regularly the students attend the program, the higher the reduction of the hazard of dropping out of school will be.

The results also indicate that gender has a significant effect. The positive slope $(B)$ means male students were more likely to drop out than female students were. The exponentiated slope $\operatorname{Exp}(B)$, which indicates the magnitude of the risk, shows that male students were 1.069 times more likely to drop out than female students were.

Ethnicity is also a significant predicator. The positive slope $(B)$ means that African American and Hispanic students were more likely to drop out than the other students were. 
The $\operatorname{Exp}(B)$ shows that African American and Hispanic students were 1.2 times more likely to drop out than non-Hispanic and non-African American students were.

LEP status also plays a significant role as a predictor. LEP students were 1.2 times more likely to drop out than non-LEP students were.

Finally, low-income status has a significant negative relationship to dropout. This indicates that the greater a student's low-income status at baseline, the less likely the student is to drop out after participation in LA's BEST.

\section{Discussion}

Previous research has documented the positive effects of afterschool programming on promoting positive student attributes for success (Durlak \& Weissberg, 2007; Fashola, 2002; Gullota, Bloom, Gullotta, \& Messina, 2009). This study further indicates that afterschool programs can have potential long-term effects on reducing the participants' hazards of dropping out of high school. This study revealed that students who had participated in the program for three or more years had significantly lower dropout rates than the nonparticipant comparison group. Furthermore, the Cox analysis showed that this effect is compounded by the intensity of participation rate; in other words, the more regularly the students attended the program, the higher the reduction of the hazard of dropping out of school. There are several research and policy implications to these findings.

As literature indicates and this study affirms, the well-documented national dropout crisis is not only an administrative issue but also an equity issue. Supporting previous studies (Editorial Projects in Education, 2007), this study also found that students from Hispanic and African American backgrounds, students from low-income backgrounds, LEP students, and male students were found to be at higher risk for dropping out of school. At the same time, the study also found that participation in the LA's BEST program could significantly reduce the students' dropout rates. In particular, LA's BEST participation appears to have a significant effect in reducing the hazard of dropping out for low-income students; that is, the greater the low-income status at the baseline, the more effective participation in LA's BEST will be in keeping these students in school.

Thus, once again, educators, youth service providers, and policy makers are reminded to rethink policy and practice in order to enhance the opportunities provided to these at-risk populations. Based on the study's findings, a few suggestions are made.

\section{Providing a comprehensive experience to enhance student engagement and participation}

First, future research could examine strategies to keep students engaged in afterschool programs. Since students who attended the programs for three or more years and students who attended the program more regularly were most able to benefit, it would be important for programs to entice students and their families to attend regularly and year after year. Aside from researching and developing more engaging curriculum and activities catered to these populations, student engagement and learning can also be enhanced by establishing policies that encourage coordination between the afterschool community and the K-12 education system. Afterschool programs can collaborate with the school system to complement what happens during the school day and join the schools' efforts to provide meaningful learning opportunities that can engage and keep kids in school. 


\section{Narrowing the equity gap}

Next, the study findings revealed that students from Hispanic and African American backgrounds, students from low-income backgrounds, and male students are at higher risk for dropping out of school. This finding is also supported by the results of the 2007 Census report. The 2007 Census revealed that after four years of high school only 51\% of African American students graduated, while $29 \%$ were still enrolled. Similarly, after four years of high school, $47 \%$ of Hispanic students graduated, while $30 \%$ were still enrolled. In light of these circumstances, it is of utmost importance for educators and policy makers to examine ways to target and attract more of these students to the afterschool programs to offset their risk of dropping out of school.

Policy makers can begin by targeting these populations at their locales and increasing access to high-quality afterschool programs in these areas. This could be done by directing federal afterschool funding to where it is needed most. They can also encourage afterschool programs and school districts to work together to develop programs (e.g., credit recovery programs, course credits, etc.) that help these students to stay on track to earning a high school diploma.

\section{Improving program quality}

While afterschool programs can be used as tools to reduce dropout rates, they can only be effective if they function as intended. That is, afterschool quality must be supported and enhanced in order to affect dropout rates. Thus, it is essential that funding is made available for researching and implementing the high-quality features of effective afterschool programs (e.g., staff quality, program implementation, resources, and instructional delivery).

Additionally, educators and policy makers can promote best practices of afterschool programs through conferences and professional development opportunities offered at the regional and state level by partnering with the local education agencies. It is also an efficient strategy to encourage shared professional development opportunities between the school and afterschool staff. This could reduce cost while increasing communication and cooperation among day and afterschool staff in working towards student success.

\section{Changing the dynamics by using a systemic approach}

Finally, the study results showed that students from low-income backgrounds benefited most by participating in the afterschool program. It would be interesting for future research to examine the dynamics at the afterschool settings and explore the factors that directly contribute to these students' benefit (e.g., caring adults, help with homework, safety, extracurricular activities, having friends in the program). The model that would emerge from such research may then be used to sustain and expand the benefits. Meanwhile, policies can be made to offer support to afterschool programs at the low-income neighborhoods to increase program quality, while specifically targeting students from low-income backgrounds and encouraging their participation in quality afterschool programs with incentives (e.g., finding out and offering activities that the students want).

At the same time, it is also important for policy makers to institute a systemic approach 
in changing the odds for at-risk youth. A systemic approach would include creating a network that brings in the afterschool community, the school system, the local and regional educational networks, the local community leaders and members, non-profit agencies, and so forth to initiate conversations and collaborations that could offer support to the students, families, and the afterschool organizations. These joint efforts and collaborations may also rally support at the society level and support policy development that hastens the implementation of strategies and regulations that can be beneficial in keeping kids in school.

In conclusion, while at-risk students have an array of challenges to face at home, school, and in the larger community, afterschool programs may offset these difficulties by providing environments that allow for short-term and long-term benefits. By reducing the hazard of dropping out, especially for low-income students, afterschool programs essentially are breaking the cycle of poverty and giving students better opportunities for growth and development. 


\section{References}

Afterschool Alliance. (2009a). Afterschool: A high school dropout prevention tool. Afterschool Alert Issue Brief, 38, 1-6.

Afterschool Alliance. (2009b). America after 3pm: The most in-depth study of how America's children spend their afternoons. Washington, DC: Author. Retrieved from http://www.afterschoolalliance.org/AA3PM.cfm

Alliance for Excellent Education. (2009, September). High school dropouts in America (Fact Sheet). Washington, DC: Author. Retrieved from http://www.all4ed.org/publication_material/fact_sheets

Arbreton, A., Sheldon, J., Bradshaw, M., \& Goldsmith, J. with Jucovy, L. \& Pepper, S. (2008). Advancing achievement: Findings from an independent evaluation of a major afterschool initiative. Oakland, CA: The James Irvine Foundation.

Birmingham, J., Pechman, E. M., Russell, C. A., \& Mielke, M. (2005). Shared features of high performing afterschool programs: A follow up to the TASC evaluation. Washington, DC: Policy Studies, Inc.

Bridgeland, J. M., Dilulio, J. J., Jr., \& Morison, K. B. (2006). The silent epidemic: perspectives of high school dropouts. A report by Civic Enterprises in association with Peter D. Hart Research Associates for the Bill \& Melinda Gates Foundation.

Brooks, J. (2006). Strengthening resilience in children and youths: Maximizing opportunities through the schools. Children \& Schools, 28(2), 69-76.

Cooper, N., Estes, C., \& Allen, L. (2004). Bouncing back. Parks \& Recreation, 39(4), 28-35.

Durlak, J. A., \& Weissberg, R. P. (2007). The impact of after-school programs that promote personal and social skills. Chicago, IL: Collaborative for Academic, Social, and Emotional Learning.

Editorial Projects in Education. (2007, June 12). Diplomas count: Ready for what? Preparing students for college, careers, and life after high school. Education Week, 26(40).

Fashola, O. S. (2002). Building effective afterschool programs. Thousand Oaks, CA: Corwin Press, Inc.

Fight Crime: Invest in Kids California. (2007). School or the Streets: Crime and California's Dropout Crisis. Oakland, CA: Author.

Gullotta, T. P., Bloom, M., Gullotta, C. F., \& Messina, J. C. (2009). A blueprint for promoting academic, social and emotional learning: The salmon program. In T. P. Gullotta, M. Bloom, C. F. Gullotta, \& J. C. Messina (Eds.), Issues in Children's and Families' Lives (Vol. 10, pp. 119-222).

Gutman, L. M., \& Midgley, C. (2000). The role of protective factors in supporting the academic achievement of poor African American students during the middle school transition. Journal of Youth and Adolescence. 29(2), 223-249.

Huang, D., Choi, K., Davis, D., Henderson, T., Kim, K., Lin, S., \& Waite, P. (2003). Evaluating the impact of LA's BEST on students' social and academic development: Study of 74 LA's BEST sites 2001-2002 final report. Los Angeles: UCLA Center for the Study of Evaluation.

Huang D., Choi K., Henderson T., Howie, J., Kim, K., Vogel, M., Waite, P., \& Yoo, S. (2004). Evaluating the impact of LA's BEST on students' social and academic development: Study of 100 LA's BEST sites 2002-2003. Los Angeles: UCLA Center for the Study of Evaluation. 
Huang D., Choi K., Henderson T., Howie, J., Kim, K., Vogel, M., Waite, P., \& Yoo, S. (2005). Examining the effects of academic skills and academic enablers taught at LA's BEST on the achievement of student participants. Los Angeles: UCLA Center for the Study of Evaluation.

Huang D., Choi K., Henderson T., Howie, J., Kim, K., Vogel, M., Yoo, S., \& Waite, P. (2004). Exploring the long-term impact of LA's BEST on students' social and academic development. Los Angeles, UCLA Center for the Study of Evaluation.

Huang, D., Coordt, A., La Torre, D., Leon, S., Miyoshi, J., Pérez, P., Peterson, C. (2007). The afterschool hours: Examining the relationship between afterschool staff-based social capital and student engagement in LA's BEST (CSE Report 712). Los Angeles: UCLA Center for the Study of Evaluation.

Huang D., De Vries, L., Golestani, C., Henderson, T., Howie, J., Kim, K., \& Waite, P. (2004). An evaluation of the Literacy Loop: An after-school tutoring program. Los Angeles: UCLA Center for the Study of Evaluation.

Huang, D., Gribbons, B., Kyung, S. K., Lee, C., \& Baker, E. V. (2000). A decade of results: The impact of LA's BEST after-school enrichment program on subsequent student achievement and performance. Los Angeles: UCLA Center for the Study of Evaluation.

Huang, D., Leon, S., La Torre, D., \& Mostafavi, S. (2008). Examining the relationship between LA's BEST program attendance and academic achievement of LA's BEST students (CRESST Report 749). Los Angeles: University of California, National Center for Research on Evaluations, Standards, and Student Testing.

Huang, D., Miyoshi, J., La Torre, D., Marshall, A., Pérez, P., \& Peterson, C. (2007). Exploring the intellectual, social and organizational capitals at LA's BEST (CSE Technical Report 714). Los Angeles: University of California, National Center for Research on Evaluation, Standards, and Student Testing (CRESST).

Laird, J., Kienzl, G., DeBell, M., \& Chapman, C. (2007). Dropout rates in the United States: 2005 (NCES 2007-059). U.S. Department of Education. Washington, DC: National Center for Educational Statistics.

Lessard, A., Fortin, L., Marcotte, D., Potvin, P., \& Royer, É. (2009). Why did they not drop out? Narratives from resilient students. The Prevention Researcher, 16(3), 21-24.

Lochner, L., \& Moretti, E. (2004). The effect of education on crime: Evidence from prison inmates, arrests, and self reports. The American Economic Review, 94 (1), 155-189.

Masten, A. S., \& Obradovic, J. (2006). Competence and resilience in development. Annals of the New York Academy of Sciences, 1094, 13-27.

Miller, B. M. (2003). Critical Hours: Afterschool programs and educational success. Quincy, MA: Nellie Mae Education Foundation.

Partnership for the $21^{\text {st }}$ Century Skills. (2009). Framework for the $21^{\text {st }}$ century learning. Tucson, AZ: Author.

Partnership for the $21^{\text {st }}$ Century Skills. (2010). $21^{\text {st }}$ century readiness for every student: A policymaker's guide. Tucson, AZ: Author.

Posner, J. K., \& Vandell, D. L. (1994). Low-income children's after-school care: Are there beneficial effects of after-school programs? Child Development, 65, 440-456.

Rouse, K. A., Bamaca-Gomez, M., \& Newman, P. (2001, August). Educationally resilient adolescents' implicit knowledge of the resilience phenomenon. Paper presented at the $109^{\text {th }}$ Annual Conference of the American Psychological Association, San Francisco, CA. 
Scott-Little, C., Hamann, M. S., \& Jurs, S. G. (2002). Evaluations of after-school programs: A meta-evaluation of methodologies and narrative summary findings. American Journal of Evaluation, 23(4), 387-419.

Siebert, A. (2005). The Resiliency Advantage: Master Change, Thrive under Pressure, and Bounce Back from Setbacks. San Francisco, CA: Berrett-Koehler Publishers, Inc.

Smink, J. \& Reimer M. S. (2005). Fifteen effective strategies for improving student attendance and truancy prevention. Clemson, SC: National dropout Prevention Center, College of health, Education, and Human Development, Clemson University.

Snyder, H., \& Sickmund, M. (1995). Juvenile offenders and victims: A national report. Washington, DC: Office of Juvenile Justice and Delinquency Prevention.

Sum, A., Khatiwada, I., \& McLaughlin, J. (2009). The consequences of dropping out of high school. Boston, MA: Northeastern University, Center for Labor Market Studies.

Townsend, L., Flisher, A. J., King, G. (2007). A systematic review of the relationship between high school dropout and substance use. Clinical Child and Family Psychological Review, 10(4), 295-317.

Ungar, M. (2004). A constructionist discourse on resilience: Multiple contexts, multiple realities among at-risk children and youth. Youth \& Society, 35(3), 341-365.

U.S. Bureau of the Census. (2010). American FactFinder Database. Retrieved from http://factfinder2.census.gov/main.html

U.S. Department of Education \& U.S. Department of Justice. (2000). Working for children and families: Safe and smart after-school programs. Washington, DC: U.S. Government Printing Office.

Vandell, D. L., Reisner, E. R., \& Pierce, K. M. (2007). Outcomes linked to high-quality afterschool programs: Longitudinal findings from the Study of Promising Afterschool Programs. Report to the Charles Stewart Mott Foundation.

Vandell, D. L., Shumow, L., \& Posner, J. (2005). After-school programs for low-income children: Differences in program quality. In J. L. Mahoney, R. W. Larson, \& J. S. Eccles (Eds.), Organized activities as contexts of development: Extracurricular activities, after-school and community programs (pp. 437-456). Mahwah, NJ: Erlbaum. 